\title{
Clinical aspects of neurolathyrism in Unnao, India
}

\author{
U K Misra MD DM MNAMS, ${ }^{1}$ V P Sharma MS DNB, ${ }^{2}$ V P Singh $\mathrm{MBBS}^{3}$ \\ ${ }^{1}$ Department of Neurology, Sanjay Gandhi Postgraduate Institute of Medical Sciences, \\ Post Box No 375, Lucknow, India; ${ }^{2}$ Rehabilitation and Artificial Limb Centre, $K G$ \\ Medical College, Lucknow, India; ${ }^{3}$ Medical Officer, Unnao, India.
}

To study the clinical picture of lathyrism in Unnao, India and compare it with that reported from other endemic areas, 41 patients from Unnao were studied. Their mean age was 42.9 years (range 22-85) and the mean duration of the illness was 17.1 years (range 2-30). They had been regularly consuming Lathyrus Sativus (LS). The patients complained of walking difficulty due to weakness and leg stiffness (32 each), and of frequency of micturition (4). Gait abnormalities included spastic gait (24), toe walking (18) and the necessary use of walking sticks (13). Weakness was mild to moderate, and was less prominent than was spasticity. In 8 patients the physical signs were asymmetrical. Peripheral neuropathy was present in only one patient, but muscle atrophy and widespread fasiculations were not found. A higher frequency of peripheral neuropathy and lower motor neuron involvement has been reported from Bangladesh and Israel. Severe spasticity in the absence of prominent weakness in lathyrism may be due to the involvement of certain specific groups of corticospinal fibres.

Keywords: lathyrism; paraplegia; plant toxin; nutritional; neurotoxicity.

\section{Introduction}

Lathyrism is a neurodegenerative disease characterised by spastic paraplegia following chronic ingestion of Lathyrus Sativus (LS). Lathyrus Sativus is a hardy plant which grows quite easily. Grains of LS are boiled in water to make a gruel (dal) and its flour is used to prepare bread. During periods of scarcity of food such as floods or droughts, LS is used as the staple food, especially by poor villagers. Three modes of presentation of neurolathyrism have been reported, the commonest being a sudden onset of leg weakness when going to sleep or when awakening from sleep. Some patients complain of a subacute onset of walking difficulty, whereas others experience an insidious progression of spastic paraparesis extending over months. Lathyrism has been reported in Asia, Africa and Europe: its current foci are in Bangladesh, China, Ethiopia, Greece, Israel, India, Spain and West Germany. ${ }^{1}$ Lathyrism is still common in certain developing countries such as Bangladesh, Ethiopia, India and Nepal, with an incidence ranging from $0.3 \%$ to $2.5 \% .^{2,3}$ In India, lathyrism is mainly reported from the states of Uttar Pradesh, Bihar and Madhya Pradesh. ${ }^{4-6}$

Most of the clinical studies on lathyrism highlight the epidemiological aspects of the disease. Though the clinical picture of lathyrism is quite uniform, certain atypical features such as peripheral neuropathy and the presence of additional lower motor neuron involvement leading to a clinical picture similar to amyotrophic lateral sclerosis (ALS) have been recently reported. ${ }^{7,8}$ Lathyrism is endemic in the district of Unnao where the last epidemic occurred in 1975-76. The epidemiological and environmental aspects of this epidemic have been studied and reported: $36 \%$ of the food samples analysed were positive for $\beta$-N-oxalylaminoalanine (BOAA) ${ }^{9}$ The clinical picture of these patients has not been reported. In the present study we report the details of the clinical picture of these patients and compare our results with those from other parts of the world. 


\section{Methods}

Forty-one patients with lathyrism from the villages under the Achalganj primary health centre of the district Unnao were examined. A detailed medical history including the present disability, the dietary history and the history of past illness was recorded. The neurological examination included gait, muscle power, reflexes, the sensations to pin-prick, joint position, and vibration. Spasticity was graded by the Ashworth score which is the sum of the score for hip (flexion and abduction), knee and ankle joints bilaterally divided by 8 . Flexor spasms were also graded. ${ }^{10}$ The power of the hip flexors, extensors, adductor, abductors; knee flexors and extensors; ankle dorsiflexors and plantar flexors of each side were graded on the MRC scale. The unweighted average of these scores gave a lower extremity power score. The activities of daily life were scored on a scale which included the assessment of ambulation, ability to work in the fields, ability to squat, urinary disturbances, and changes in occupation after onset of the illness. The scoring was done giving equal weight to the subset of the above parameters. The minimum score was 5 and the maximum 18 . In 8 randomly selected patients radiographs of the cervical and thoracolumbar spine, AP and lateral views, were taken. Urinalysis, haemoglobin, blood counts, random blood sugar, blood urea, serum creatinine and serum protein were also estimated. In 2 patients computerised tomography of the spine from T6 to L1 using $2 \mathrm{~mm}$ cuts was performed. The dependence of the lower extremity power score, Ashworth score, cross adductor reflex and ankle clonus on the patient's disability (use of walking sticks) were evaluated by $x^{2}$ test.

\section{Observations}

Forty-one patients with lathyrism were examined, all of whom were Hindu male farmers of middle or low socioeconomic status. They had been consuming LS since childhood, and their consumption reached up to $105.5 \mathrm{gm}$ daily (range 70-250). After developing leg weakness, 14 patients stopped consuming LS; however, the others continued to take LS although less frequently and in a smaller quantity. Fourteen took nonvegetarian food, and 14 were social drinkers.

The mean age of the patients was 43 years (range 22-85). The onset of illness was about 17 years (22) and 22 years earlier (11), though sporadic cases were also seen and one patient developed lathyrism only 2 years earlier. The symptoms reported by these patients are shown in Table I. The leg weakness developed acutely, reaching its peak within 7 days of the onset in 20 patients. In others the weakness developed slowly, taking 1-4 weeks in 13 and more than 4 weeks in 8 patients. Leg stiffness was the most frequent complaint. The patients were of good build, there was no pallor, pedal oedema nor any sign of vitamin deficiency. They had a characteristic posture comprising hip flexion and adduction, knee flexion, plantar flexion of ankles and toes (18 patients) (Fig 1). Hip flexion resulted in secondary spinal flexion in 7 patients. The muscle spasm restricted movements at the knee and ankle joints, resulting in a spastic gait (24). Some patients with marked adductor spasticity walked with a scissoring gait (14).

Spasticity in these patients was out of proportion compared to their weakness, and appeared to be the most significant disability. A patient was unable to lie supine because of severe spasticity (Fig 2). This degree of spasticity is not commonly seen in other neurological disorders. Stiffness and walking difficulty in most patients was aggravated during the winter. Three patients complained of grade I flexor spasms, usually at night. In contrast to the severe

Table I Symptoms in the patients with lathyrism

\begin{tabular}{lcc}
\hline Symptoms & No & Percent \\
\hline Walking difficulty & 32 & 78 \\
Stiffness & 32 & 78 \\
Frequency or urgency & & \\
$\quad$ of micturition & 4 & 10 \\
Tingling, numbness & 3 & 7 \\
Cramps & 2 & 5 \\
\hline
\end{tabular}




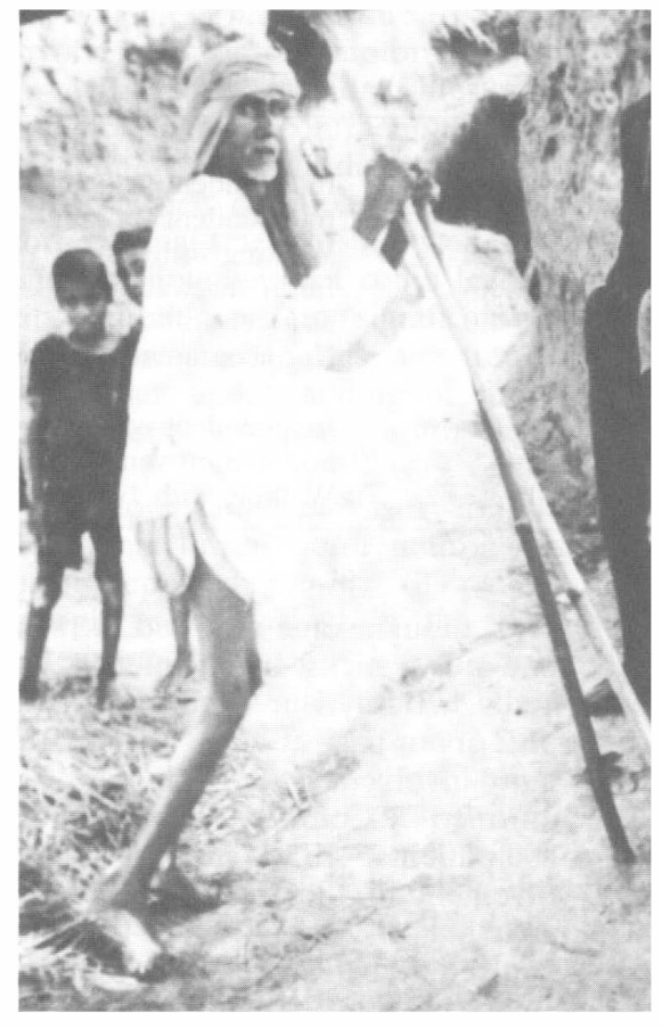

Figure 1 A patient with lathyrism showing the characteristic posture.

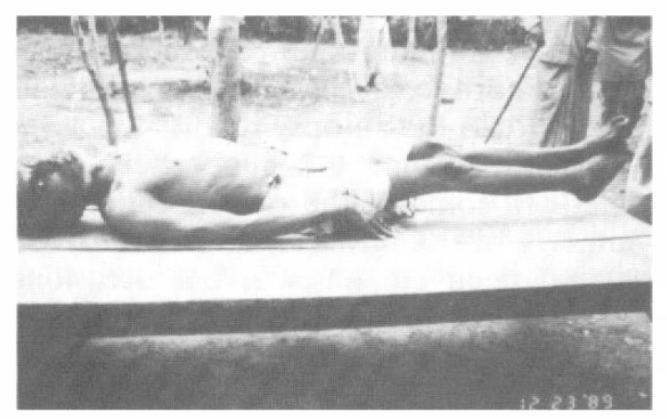

Figure 2 A patient with lathyrism unable to lie supine because of severe spasticity.

spasticity, the leg weakness was mild to moderate in most patients, being between grades 2.9 and 5. Most patients could walk unaided, but 11 required one, and 2 needed two sticks for walking. The upper limbs were normal in all of the patients except for 2 ; in one, tone of upper limbs muscles was increased, and in the other there was hyperreflexia and muscle weakness of grade IV. In 35 patients activities of daily life (ADL) were recorded. The ADL score ranged between 6 and 10 in 27 and between 11 and 15 in 11 patients, suggesting mild to moderate impairment. The physical signs were symmetrical in most patients with 8 exceptions. Slight asymmetry of muscle power was present in 5 patients. The asymmetry of pyramidal signs was evidenced by the asymmetry of spasticity, unilateral ankle clonus and unilateral Babinski sign in one patient each. The physical signs in the lathyrism patients are summarised in Table II.

The symptoms were stationary in most, but one patient complained of increasing weakness and walking difficulty for 4 years, though his symptoms had remained unchanged for the previous 17 years. Ten patients reported variable degrees of improvement. The improvement started after a mean duration of 1.4 months (range $0.3-2$ ) following the onset of weakness, and continued for 7.4 months (range 0.8-48). The extent and duration of improvement is shown in Table III. The improvement cannot be attributed to any specific change in the dietary habit because 4 patients were still consuming LS and 6 had stopped its consumption completely-but in them the improvement had started long before the consumption of LS had stopped. Cervical

Table II Physical signs in the patients with lathyrism

\begin{tabular}{|c|c|c|c|}
\hline Signs & & No & Percent \\
\hline Spastic gait & & 24 & 59 \\
\hline Toe walking & & 18 & 44 \\
\hline Flexion of spine & & 7 & 17 \\
\hline Use of walking stick & & 13 & 32 \\
\hline \multirow[t]{3}{*}{ Ashworth score } & $2-3$ & 18 & 44 \\
\hline & $3.1-4$ & 20 & 49 \\
\hline & $>4.1$ & 2 & 5 \\
\hline Flexor spasms & & 3 & 7 \\
\hline Cross adductor reflex & & 33 & 80 \\
\hline Clonus & & 16 & 39 \\
\hline Extensor plantar sign & & 37 & 90 \\
\hline \multicolumn{4}{|l|}{ Asymmetry of signs } \\
\hline Power & & 5 & 12 \\
\hline Pyramidal signs & & 4 & 10 \\
\hline
\end{tabular}


Table III Functional recovery in patients with lathyrism

\begin{tabular}{cclcl}
\hline Serial No & Patient No Peak disability & Duration (months) & Final deficit \\
\hline 1 & 2 & Bed ridden & $2-4$ & Walking with 2 sticks \\
2 & 4 & 1 stick & $1-2$ & Independent walking \\
3 & 9 & Bed ridden & $1.5-1.8$ & Independent walking \\
4 & 10 & Bed ridden & $0.5-2.0$ & Walking with 1 stick \\
5 & 13 & 1 stick & $0.3-0.8$ & Improved walking \\
6 & 14 & Inability to get up & $0.8-4.0$ & Can get up \\
7 & 17 & Occasional incontinence & $0.5-2.0$ & No incontinence \\
& & of urine & $2-48$ & Independent walking \\
8 & 20 & Bed ridden & $1-4$ & Some improvement \\
9 & 32 & Weakness in walking & $1-3$ & Walking with 1 stick \\
\hline
\end{tabular}

and lumbar spine radiographs revealed mild to moderate changes suggestive of spondylosis in 5 patients. Haemoglobin (14.7 \pm $2.3 \mathrm{gm} / \mathrm{dl})$, blood urea $(25.6 \pm 7.3 \mathrm{mg} / \mathrm{dl})$, serum creatinine $(1.2 \pm 0.4 \mathrm{mg} / \mathrm{dl})$, blood sugar $(74.3 \pm 8.1 \mathrm{mg} / \mathrm{dl})$, serum protein $(7.8 \pm 0.7 \mathrm{gm} / \mathrm{dl})$ and urinalysis were normal. Computerised axial tomography of the spine in both the patients studied was normal. The disability of the patients was significantly dependent on spasticity $\left(x^{2}=4.49, p<0.05\right)$ but not on muscle power $\left(x^{2}=0.003\right)$, cross adductor reflex $\left(x^{2}=0.001\right)$ and clonus $\left(x^{2}=2.9\right)$.

\section{Discussion}

Most of the patients in this study had developed lathyrism in the epidemic of 1975-76, though sporadic cases have been occurring because LS continues to be cultivated and consumed in the district of Unnao. The clinical picture of these patients was characteristic of lathyrism: the development of a pure motor spastic paraplegia in a geographical area known to be endemic for lathyrism; a progressive course; and absence of sensory signs with minimal or no involvement of the sphincters. ${ }^{5}$ None of our patients was female; and none was very severely disabled (crawling stage). The rarity of lathyrism in females has also been reported in other studies, and is attributed to underreporting of the female cases due to shyness, a lesser intake of LS, and from hormonal influences. ${ }^{6}$ All our patients were ambulatory, though some required the support of one or two sticks. Involvement of the upper limbs in lathyrism is rare and was present in 2 of our patients. The rarity of the upper limb involvement in lathyrism has been confirmed by Cohn et al, who found it in 4 of 200 patients. $^{8}$ In the autopsy studies the involvement of the thoracolumbar ${ }^{11,12}$ and lumbar region ${ }^{13}$ of the spinal cord has been reported. This prediliction for the thoracolumbar region may be due to the special affinity of this region for lathyrus toxin. The other histopathological changes in lathyrism have included degeneration of Betz cells in the cerebral cortex, loss of myelin and axons in the pyramidal tract, occasional swelling and degeneration of anterior horn cells and swelling of Galls nuclei $^{11-13}$. In the autopsy reports the asymmetrical involvement has not been highlighted. In some of the clinical reports the symmetry of the physical signs in lathyrism has also been emphasised, but occasional asymmetry has also been reported. ${ }^{1}$ In our study a high frequency of asymmetry of physical signs was noted. Not only was there asymmetry of weakness but also of the pyramidal signs. Analysis of patients from other endemic areas as well is required to confirm the asymmetrical involvement in lathyrism.

In our patients spasticity was the most significant disability. The patient's disability significantly depended on the degree of spasticity $(p<0.05)$ but not on muscle power, cross adductor reflex and clonus. The discrepancy between the spasticity and 
the weakness may be due to a differential involvement of the motor pathways. The large diameter pyramidal fibres are responsible for phasic contraction whereas the function of the small diameter corticospinal fibres, which constitute over $90 \%$ of the corticospinal tract, ${ }^{14}$ is not well understood; but their involvement could lead to spasticity without producing significant weakness. Further studies in this direction may improve our understanding of the different components of upper motor neuron syndrome.

In longstanding cases of lathyrism additional lower motor neuron signs have been reported in $7 \%$ of patients. The atrophy was marked in the flexors and extensors of the feet. ${ }^{8}$ In our study we did not find any evidence of muscle atrophy or widespread fasciculations. In a report from Unnao a high frequency of calf fasciculations was reported in patients with lathyrism, but their significance was not mentioned. ${ }^{9}$ In our study, 3 patients had tingling numbness and paresthesiae, and one patient also had loss of the ankle reflex, suggesting peripheral neuropathy at least in the latter patient. Peripheral neuropathy in severe cases of neurolathyrism has been reported. ${ }^{15}$ In 200 patients with longstanding lathyrism, sensory peripheral neuropathy was present in 12 , their nerve conduction velocity was slow and the histopathological changes were consistent with segmental demyelination. ${ }^{8}$ In a study from Bangladesh, mild peripheral neuropathy was reported in 4 of the 16 patients. ${ }^{7}$ In our study the frequency of neuropathy was much less than that reported from Israel, Bangladesh and Spain. ${ }^{7,8}$ The role of concomitant nutritional deficiency in producing peripheral neuropathy cannot be excluded, although some investigators from Bangladesh have noted that patients with lathyrism were well nourished. ${ }^{6}$ Detailed evaluation of the nutritional status of the patients with lathyrism is needed to resolve this issue.

Lathyrism generally has a stationary course. Late deterioration in one of our patients for 4 years, after the symptoms had remained stationary for over 17 years, may be due to secondary degenerative changes. An interaction between aging and environ- mental factors accounting for such deterioration has been suggested. ${ }^{17}$ Similar deterioration has been reported in the patients with lathyrism who had developed lower motor signs resembling $\mathrm{ALS},{ }^{8}$ but before presuming such conclusions, other common conditions such as spondylotic myelopathy should be excluded. In the early stage of the disease a variable degree of improvement has been reported. In our study also, improvement occurred in the initial period of the illness in some patients. The initial symptoms such as cramps and paresthesiae commonly precede the development of leg weakness and seem to wane or disappear once the intake of LS has been stopped or reduced. ${ }^{8,18}$ Concurrently there is an early improvement of limb strength which is sometimes substantial. Early and commonly reversible symptoms of global muscle cramping, urgency and frequency of micturition, nocturnal erection and ejaculation suggest that LS can result in diffuse and transitory CNS excitation of somatic motor and autonomic functions. ${ }^{8}$ After the acute presenting symptoms of lathyrism have subsided, the patient develops varying degrees of spastic paraplegia because of pyramidal tract dysfunction. The neurotoxin responsible for this irreversible damage is yet to be identified. The extracts of LS and BOAA are known to produce varying degrees of limb paralysis in animals given extracts intrathecally, ${ }^{19,20}$ but no experimental evidence has been produced to show toxicity of LS and BOAA following oral administration. ${ }^{21}$ The role and mechanism of BOAA in producing pyramidal tract dysfunction requires further studies.

\section{Conclusions}

The results of this study are that asymmetry of physical signs in lathyrism was found in $20 \%$ of our patients; peripheral neuropathy was uncommon and muscle atrophy was not found in any of our patients; spasticity was the most prominent sign and seemed to be a significant cause of the patient's disability. In 7 patients there was spasticity and milder weakness which may be due to selective involvement of the pyramidal tract. Further studies in this direction are recommended. 


\section{References}

1 Ludolph AC, Hugon J, Dwivedi MP, Shaumburg HH, Spancer PS (1987) Studies on the etiology and pathogenesis of motor neuron disease. Brain 110: 149-165.

2 Kaul AK, Islam MQ (1982) Khesari (Lathyrus Sativus) cultivation in Bangladesh and lathyrism. Bangladesh Agricultural Research Council, Dhaka: 1-11.

3 Gopalan C, Dwivedi MP, Singh SP (1983) Lathyrism problem-current status and new dimensions. Scientific Report No 2, Nutrition Foundation of India, New Delhi.

4 Govil KK, Gupta BM, Chakravarty NL, Bhatnagar DP, Pant KG (1959) Field investigation of lathyrism in Uttar Pradesh. $1959 \mathrm{~J}$ Ind Med Assoc 33: 499-506.

5 Prasad LS, Sharan RK (1969) Lathyrism. In: P J Vinken, G W Bruyn, editors. Handbook of Neurology. Vol 36. North Holland Publishing Company, Amsterdam: 505-515.

6 Dwivedi MP, Prasad BG (1964) An epidemiological study of lathyrism in the district of Rewa, Madhya Pradesh. J Ind Med Res 52: 81-114.

7 Hugon J, Ludolph AC, Gimenez-Roldon S, Haq A, Spencer PS (1990) Electrophysiological evaluation of human lathyrism. Results in Bangladesh and Spain. In: F Clifford, Forbes $\mathrm{H}$ Norris, editors. ALS New advances in Taxicology and Epidemiology. Smith Gordan, London: 49-56.

8 Cohn DF, Streifler M (1981) Human lathyrism: a followup study of 200 patients. Part 1: Clinical investigations. Archives Suisses de Neurologic Neurocehirugic et de Psychiatrie 128: 151-156.

9 Industrial Toxiology Research Centre (1976) Outbreak of paralysis in some villages of Unnao district Uttar Pradesh - a preliminary epidemiological study 342/B. Industrial Toxicology Research Centre, Lucknow.

10 Penn RD, Savoy SM, Corcos D, Latsh M, Gottlieb G, Parke B et al (1983) Intrathecal beclofen for severe spinal spasticity. $N$ Engl J Med 320: 1517-1521.

11 Ganpathy KT, Dwivedi MP (1961) Studies on clinical epidemiology of lathyrism Rewa. Indian Council of Medical Research, Gandhi Memorial Hospital. Lathyrism Enquiry Field Unit P29.

12 Sachdev S, Sachdev JC, Devinder P (1969) Morphological study in a case of lathyrism. 1969: J Ind Med Assoc 52: $320-322$.

13 Striefler M, Cohn DF, Hirano A, Schujman E (1976) The central nervous system in a case of neurolathyrism. Neurology 27: 1176-1178.

14 Takahashi K (1965) Slow and fast group of pyramidal cells and their respective membrane properties. $J$ Neurophysiol 28: 908-924.

15 Mertens HG (1947) Zur Klinik des Lathyrismus. Nervenarzt 18: 493-499.

16 Mannan MA (1985) Lathyrism. Bangladesh J Neurosci 18: 5-8.

17 Clane DB, McGeer E, Eisen A, Spencer P (1986) Alzheimer's disease, Parkinson's disease and motoneuron disease: Ageing and environment. Lancet 11: 1067-1070.

18 Kessler A (1947) Lathyrismus. Montatsschirft fur Pyrchiatrie und Neurologie 113: 345-375.

19 Rao SLN, Sarma PS, Mani KS, Rao TRR, Sriramachari S (1967) Experimental neurolathyrism in monkeys. Nature 214: 610-611.

20 Chase RA, Pearson S, Nunn PB, Lantos PL (1985) Comparative toxicities of $\alpha$ and $\beta$-N-oxalyl- $\alpha$-a, $\beta$-diaminopropionic acids to rat spinal cord. Neurosci Lett 55: 89-94.

21 Spencer PS, Schanmberg HH (1983) Lathyrism: a neurotoxic disease. Neurobehav Toxicol Teratol 5: $625-629$. 